\title{
SGANZERLA COVER
}

\author{
Victor da Rosa \\ Universidade Federal de Santa Catarina
}

\begin{abstract}
Resumo: Neste artigo, realizo uma leitura do cinema de Rogério Sganzerla, desde o clássico $O$ bandido da luz vermelha até os documentários filmados na década de oitenta, a partir de duas noções centrais: cover e over. Para isso, parto de uma controvérsia com o ensaio de Ismail Xavier, Alegorias do subdesenvolvimento, em que o crítico realiza uma leitura do cinema brasileiro da década de sessenta através do conceito de alegoria; depois releio uma série de textos críticos do próprio Sganzerla, publicados em Edifício Sganzerla, procurando repensar as ideias de "herói vazio" ou "cinema impuro" e sugerindo assim uma nova relação do seu cinema com o tempo e a representação; então busco articular tais ideias com certos procedimentos de vanguarda, como a falsificação, a cópia, o clichê e a colagem; e finalmente procuro mostrar que, no cinema de Sganzerla, a partir principalmente de suas reflexões sobre Orson Welles, a voz é usada de maneira a deformar a interpretação naturalista.
\end{abstract}

Palavras-chave: Sganzerla. Cover. Over.

\section{Nem tudo é Brasil}

Em um ensaio sobre a alegoria do subdesenvolvimento no cinema brasileiro - que pode ser encarado também como um ensaio sobre alegoria $e$ subdesenvolvimento, já que a figura da alegoria neste caso não deve ser aceita com naturalidade -, o crítico Ismail Xavier sugere uma leitura de $O$ Bandido da Luz Vermelha que me parece, para dizer o mínimo, ambivalente. De fato, o livro inteiro de Ismail, no qual o ensaio sobre Sganzerla ocupa apenas uma de suas partes, pretende refazer uma leitura do cinema brasileiro da década de sessenta, mais especificamente entre 1964 e 1970, a partir de uma chave que se torna evidente nas suas primeiras linhas: a realidade nacional. Os filmes eleitos vão desde Brasil Ano 2000, de Walter Lima Jr, até Bang Bang, de Andrea Tonacci, passando naturalmente pelo thriller de Sganzerla. Trocando em miúdos, a tese de Ismail nos diz que é através do recurso às alegorias, articulado com a consciência de classe, que os filmes em questão estabelecem uma aproximação com a realidade brasileira.

Digo que a alegoria não deve ser aceita com naturalidade porque nela está implícito

\section{(i) $\odot$}

EY NC No Esta obra está licenciada sob uma Licença Creative Commons.

\footnotetext{
Doutorando em Teoria Literária pela Universidade Federal de Santa Catarina (UFSC). Contato: victordarosa@gmail.com. Dedico este ensaio ao professor Jair Fonseca, que me ensinou quase tudo que sei sobre Tropicalismo.
} 
um modo específico de leitura, a saber: uma opção por aquilo que Ismail chama de "autoconsciência plena da representação" (XAVIER, 1993, p. 15). Aliás, creio que o significante mais sintomático do título do livro de Ismail seja justamente a alegoria e não, como parece, o subdesenvolvimento. O próprio crítico define alegoria através da noção de referência, como "mensagem cifrada, referida a uma 'outra cena' não atualizada em imagem e som”. E depois afirma: "A disposição do espectador de querer decifrar pode encontrar ancoragem, mais ou menos definida, quando esta 'outra cena' dá sinais de ser o contexto nacional tomado como uma totalidade" (XAVIER, 1993, p. 11). O contexto nacional, em todo caso, seria marcado pelo emblema da "condição periférica", pedra de toque que motiva toda a análise de Ismail, mas é pela figura da alegoria que o crítico parece marcar a sua posição de leitura.

A alegoria, ao menos neste caso, é definida como mensagem mais ou menos estável, certa identificação que permite associar, com alguma segurança, ficção e realidade nacional. Para Ismail Xavier, em poucas palavras, o cinema da década de sessenta, sob os três signos que a história tratou de naturalizar (cinema novo, tropicália e cinema marginal), reflete o subdesenvolvimento da periferia. Ismail ainda afirma a teleologia - ou seja, a suposição de uma narrativa que avança através da causalidade, e não de uma narrativa que circula em torno de si - como forma de organização do tempo. Por mais que o crítico enfatize que sua noção de alegoria guarda diferentes proporções em relação a cada cineasta (haveria alegorias mais pedagógicas e menos pedagógicas), o crítico não abre mão da relação quase transparente entre manifestação e essência. Ou nas palavras do próprio Ismail: “[...] a forte presença, nos filmes, de uma interação entre mise-em-scène e comentário explícito" (XAVIER, 1993, p. 14). O que está em jogo em tal noção de alegoria consiste no entendimento de que a linguagem, afinal, é uma ação transparente e comunicativa, ou seja, uma mensagem que precisa e deve ser decifrada.

O que me parece ambivalente é que na própria análise que Ismail faz d' $O$ Bandido da Luz Vermelha - filme que representaria, em todo caso, ao lado de Terra em Transe, o modelo menos evidente da alegoria -, o crítico parece reconhecer usos de linguagem que servem justamente para problematizar a narrativa teleológica, pedagógica, embora seu caminho naturalmente não seja este. O caminho de Ismail não está ligado à procura pela invenção, mas pela origem; não enfatiza a indecisão, a falta de razão e a opacidade de uma narrativa que não faz mais do que voltar para o mesmo lugar, e sim a progressão e o sentido final, justamente o telos. O cinema de Sganzerla, portanto, mesmo em sua leitura, seria 
antiteleológico, estaria mais "afinado ao alegorismo moderno e sua recusa de síntese", mas não deixa de ser ainda um reflexo e um espelho da realidade nacional. O emblema periférico da estética da fome seria, no filme de Sganzerla, o emblema do lixo. E o espaço da Boca do Lixo, para Ismail, em uma palavra, é o próprio Brasil, "paradigma de urbanidade [...] cuja engrenagem globaliza a experiência nacional em termos de boçalidade" (XAVIER, 1993, p. 104).

No entanto, fica claro que o cinema de Rogério Sganzerla, pelo seu potencial do paradoxo, da indecisão e do esvaziamento, como se verá adiante, é a força que oferece mais resistência para a tese de Ismail Xavier. De certo modo, a leitura que Ismail faz d'O Bandido da Luz Vermelha lança mão das mesmas estratégias que Roberto Schwarcz usa para ler as Memórias Póstumas de Brás Cubas. Com a dificuldade de encontrar as pistas mais evidentes da presença dos emblemas nacionais, Ismail recorre ao dado formal, estruturante. No romance de Machado de Assis, radicalmente antiteleológico - basta lembrar que a narrativa acontece exatamente de trás pra frente e as memórias são contadas por um defunto delirante Schwarcz vai procurar o Brasil na própria volubilidade formal da narrativa. Por sua vez, na conclusão de seu ensaio, Ismail vê na fragmentação e "na forma mecânica da justaposição" os "traços que assinalam uma formação social não integrada organicamente, onde os atropelos e ‘invasões’ prevalecem sobre os processos endógenos” (XAVIER, 1993, p. 103).

Há alguns momentos da análise de Ismail que sua tese se enfraquece especialmente. Ao sugerir que $O$ Bandido encena "a ansiedade por uma teleologia perdida", por exemplo, Ismail parece ignorar até mesmo o pensamento de Rogério Sganzerla sobre o tempo no cinema, presente em seus textos críticos publicados antes de se tornar cineasta. Em um das primeiras análises publicadas no suplemento literário d'O Estado de São Paulo, ainda em 1964 - uma análise d'Os Cafajestes, de Ruy Guerra -, Sganzerla enfatiza como procedimento forte do filme justamente a sua estrutura circular. O texto abre com as seguintes palavras: “A repetição constante, na estrutura circular, da impossibilidade do amor, ganha, no cinema, possibilidades absolutamente dinâmicas" (SGANZERLA, 2010, p. 30). Ao analisar a última cena, Sganzerla enfatiza "a volta obcecada ao ponto de partida", "o gosto pelo desconhecimento" e "a busca do mistério" (SGANZERLA, 2010, p. 31). O então jovem crítico irá desenvolver estas noções em análises posteriores; voltarei a elas.

Seja como for, Ismail Xavier não deixa de reconhecer os procedimentos de vanguarda que o filme de Sganzerla atualiza, principalmente a apropriação e a colagem, e não deixa de reconhecer também que a biografia de seu protagonista "não busca propriamente 
traçar um caráter" (XAVIER, 1993, p. 72) - e dizer caráter é dizer presença, substância de representação. Depois, Ismail reconhece inclusive a falta de cronologia e de ações encadeadas presentes nas primeiras cenas do filme, que lembram aliás as últimas cenas e sugerem, a sua maneira, um prenúncio de circularidades que atravessa todo o filme. "Seu presente é rotina e repetição", conclui o crítico, após descrever uma série de ações de um personagem que não possui objetivos maiores e nem mesmo a aura de herói. Por sua vez, seu retrato é uma composição entre atributos desconexos e disparatados, que possui por exemplo os traços que seguem:

[...] ex-campeão de futebol de botão, o neto de Chico Diabo, o brasileiro que matou Solano Lopes na Guerra do Paraguai, um herdeiro dos astecas e dos tapuias, uma figura selvagem do século XVI perdida na selva de asfalto, um cafajeste, ex-turista sexual, nudista forçado a casar na polícia, fanfarrão, mau caráter, um blefe. [...] um ladrão analfabeto, um mentiroso com um imenso repertório de palavrões. (XAVIER, 1993, p. 79)

O ponto do ensaio de Ismail que oferece maior interesse, justamente por ser o ponto mais ambivalente, é quando o crítico passa a tentar responder uma pergunta que ele mesmo se faz: “(...) face a tal desestabilização geral, como discutir a formação das identidades, do heróitítulo em especial?" (XAVIER, 1993, p. 80). O tema da falta de identidade do protagonista será um verdadeiro estorvo para as conclusões de Ismail. Se não há identidade, formação de caráter, alguma moral ou mesmo uma mensagem, também não há matéria estável de representação. Se o personagem permanece opaco, e principalmente se a própria narrativa permanece opaca, como é possível construir alegoria, que pressupõe justamente certa transparência? Ismail dedica uma parte de seu ensaio, que intitula como "As ruínas da identidade", para discutir estas noções. Neste momento, o crítico percebe os deslizamentos de sentido que aparecem mesmo quando o protagonista se define: "eu sou um boçal", já que o tom da autodepreciação joga com a ambiguidade do efeito: "ao se apropriar do xingamento, o bandido se reafirma". (XAVIER, 1993, p. 86)

De fato, a primeira fala de Jorginho - personagem que, aliás, por ser criminoso, possui uma série de identidades falsas -, é justamente uma pergunta (uma dúvida) sobre a própria identidade: “quem eu sou?" Pode-se dizer que a narrativa de Sganzerla se apoia em grande parte sobre esta pergunta e a partir dela desenvolve vários de seus argumentos. Em todo caso, se é razoável esperar uma espécie de revelação identitária de Jorginho durante o filme, aos poucos o leitor vai se dando conta de que o vazio da dúvida, ao invés de se resolver, se expande ainda mais. É como se a proliferação de identidades do protagonista fizesse deslizar todas as formas de reter uma imagem, aumentando a dúvida inicial. Sua morte 
bizarra na última cena do filme, sem qualquer resquício de monumentalidade, é o indício final de que não há retrato possível. Se existem inúmeras identidades, afinal, então não existe nenhuma. O que está cindido, com a cisão da própria identidade de Jorginho, deve ser a alegoria do nacional. Ao invés de avançar em direção a um encontro, a alguma finalização, a narrativa recua, ao contrário, gira em torno de si própria, retorna para o ponto onde começou, uma pergunta sem resposta. A última fala do filme, enunciada desta vez por uma vez em off, é outra pergunta, agora vazia, cética e certamente debochada: "e daí!?" Nisso parece se desfazer, segundo o meu ponto de vista, a idéia de que há uma espécie de lamento, no cinema de Sganzerla, por uma "teleologia perdida".

Em todo caso, a teleologia está perdida, e nisso Ismail acerta. O que não se perde é a possibilidade de criar, e isso sem qualquer indício de saudosismo. Ora, não há saudades no cinema de Sganzerla. E não há saudades porque não há idealização do sentido. Seu olhar em direção ao passado, e mesmo em direção ao passado nacional, como mostra sua série de filmes sobre o compositor Noel Rosa, por exemplo, tem algo do procedimento do arqueólogo, que busca refazer as camadas de discurso escondidas por baixo da superfície da história. Pode-se dizer que o cinema de Rogério não procura apenas o que existiu e se perdeu, atribuindo certa dose de lamento a esta perda, e sim o que sempre permaneceu estranho (e sobretudo invisível) à história. De outra maneira, Rogério sabe que todo objeto é um objeto perdido. Por sua vez, seu olhar em direção ao futuro, mais inconsciente e instintivo, traz sempre algo de profético. Seu cinema tem certo atraso, ou seja, é subdesenvolvido, mas também tem profecia, velocidade. A alegoria, segundo o modo pelo qual a crítica de Ismail a solicita, possui um forte caráter disciplinador: não suporta a ambiguidade, as reviravoltas e o paradoxo. De outra maneira, sua crítica parece enfatizar os fatos mais evidentes do tempo presente. E o bandido não se dirige aos esclarecidos.

Em Nem Tudo é Verdade, a personagem de Helena Ignez diz o seguinte sobre Welles: "deixou de ser americano e não consegue ser brasileiro; perdeu a identidade." Não se trata de dizer, no entanto, que o cinema de Rogério Sganzerla não lida com a memória do nacional. Talvez seja interessante pensar o nacional, neste caso, como um material entre outros, e não como imagem organizadora, tampouco como sentido único. Com seu cinema, pode-se dizer que Rogério faz uso do nacional, e não somente incorpora o nacional como direção. Trata-se, em outras palavras, do nacional antes ou mesmo além do nacional. A trilha sonora que fecha $O$ Bandido da Luz Vermelha, neste sentido, parece sintomática: uma colagem de batuques de macumba com a guitarra ruidosa de Jimi Hendrix. Como em 
Batmacumba, canção chave da Tropicália, Rogério Sganzerla mistura a macumba com Batman, põe em contato exterior e interior. Enfim, se um dos gestos de Sganzerla, com a passagem de Orson Welles pelo Brasil, consiste em incluir a negativa "nem" ao título "tudo é verdade", provável título que teria o filme de Welles, neste caso, alterando portanto o nosso modo de ler uma passagem determinada da história, também é possível sugerir uma correção ao modo como Ismail Xavier, em seu ensaio, realiza a leitura d'O Bandido da Luz Vermelha: nem tudo é Brasil.

\section{Câmera Cover}

O que está em questão, afinal, é se a alegoria se apresenta como figura de linguagem que melhor pode dar conta dos problemas que o cinema de Rogério Sganzerla propõe. Neste caso, o melhor crítico de Sganzerla ainda parece ser o próprio cineasta. Nos textos que escreve quando não tinha vinte anos de idade ainda, publicados principalmente no Suplemento Literário do Estadão, mas quase sempre sobre cinema, Rogério realiza um duplo movimento. Por um lado, acompanha com textos analíticos, quase sempre escritos com certo fôlego, a produção cinematográfica (brasileira e internacional) em debate no final da década de sessenta, além de textos que poderíamos chamar de ensaios teóricos; por outro, parece também construir as bases - estéticas, éticas, digamos assim, por falta de melhor nome - do que viria a ser a sua trajetória como cineasta. É interessante notar a maneira como estes textos do crítico Rogério Sganzerla passam a ecoar nos seus próprios filmes, através de suas temáticas mas também através de seus procedimentos, deixando a impressão curiosa de que, afinal, Sganzerla escrevia apenas sobre o cinema que realizaria durante as três décadas seguintes.

É consenso afirmar que "Não foi só com a câmera de filmar que Rogério Sganzerla fez cinema", como escreve José Geraldo Couto na orelha do livro que reúne parte dos textos críticos de Rogério (SGANZERLA, 2010) - consenso que, aliás, é insinuado pelo próprio cineasta, através de algumas de suas entrevistas, e repetido por uma série de críticos nos anos seguintes. Se o consenso existe, parece que nenhum crítico se dedicou a analisar com detalhes o modo como é construído. Um dos traços mais evidentes desta operação, e nem poderia ser diferente, está ligado às escolhas dos filmes que Rogério analisava. Seu paideuma ou seu edifício, para usar a expressão que os organizadores de seus textos críticos também usaram, vai de Orson Welles a Jean-Luc Godard, passando por Noel Rosa, João Gilberto e Jimi Hendrix, "o artista mais importante deste século", nas palavras do próprio Rogério, com o 
exagero que lhe era peculiar. Através destas referências, Jair Tadeu da Fonseca sugere alguns pontos de contato que pretendo desenvolver mais adiante:

Welles, por reinventar a linguagem cinematográfica, pensar o cinema e até criar imagens inéditas do Brasil; Noel, por introduzir uma nova poesia urbana na música popular brasileira, com amor, humor e dor; João Gilberto, por criar uma batida inaudita e uma bossa nova de cantar, na música popular brasileira internacional; Hendrix, por transformar a microfonia em música, numa orquestração radical de sons e cores na guitarra elétrica. (FONSECA, 2010, p. 30)

Em um texto que chama a atenção pela precocidade, intitulado "A câmera cínica", publicado em 1964 - Rogério estava com exatos 18 anos na ocasião e era um estudante desinteressado de Direito -, o crítico já intui, através da evidência da imagem no cinema, que a linguagem deve ser pensada pelo regime da aparência, como "pura visibilidade". O filme de Godard, principalmente Uma mulher é uma mulher, na medida em que suprime qualquer noção adjetiva - também no título, como se vê, mas sobretudo na maneira de filmar -, tornase o paradigma de Rogério para o desenvolvimento de sua ideia de câmera cínica. De outra maneira, a câmera cínica será para Rogério algo muito próximo daquilo que, mais de dez anos depois, será o "neutro" para Roland Barthes, ou seja: "A câmera cínica é a câmera que deixou de participar do movimento dramático, distanciou-se dele; olha-o indiferentemente, olha-o apenas"; e ainda, talvez com maior precisão: "A câmera realiza, então, um trabalho difícil: o esvaziamento do heroísmo dos personagens" (SGANZERLA, 2010, p. 38).

O que interessa do cinema de Godard para Rogério Sganzerla são duas coisas: a opacidade da imagem e o despojamento. É neste texto que aparece a primeira menção a um conceito que reaparece em outros textos de Rogério: "o herói vazio", retomado às vezes como "herói fechado", que se refere à negação da psicologia, do personagem que não se deixa conhecer, e que tem como precursor e protótipo justamente o Cidadão Kane, de Orson Welles. Em um texto intitulado "Becos sem saída", Rogério explica: "O filme não se dispõe a 'explicar' ou definir o interior do personagem, seja através da psicologia, psicanálise, intimismo, etc. Não há aquela 'análise clínica' porque o ser é impenetrável.” (SGANZERLA, 2010, p. 41). Existe uma cena do clássico de Welles que será uma das obsessões de Rogério, comentada em alguns de seus textos críticos e recuperada mesmo em alguns de seus filmes, que é a cena da morte de Kane:

O precursor e também protótipo do herói fechado é, provavelmente, Cidadão Kane (1941), que pronuncia no leito de morte uma palavra desconhecida e inexplicável ("Rosebud"). Um repórter, incumbido de descobrir o seu significado, entrevista os contemporâneos de Kane, mas nem estes personagens conseguem defini-lo. A crise interior do personagem está diretamente ligada à palavra, percebe-se claramente que 
há uma crise profunda. Mas esta é inacessível, impenetrável: sabe-se de sua existência, mas não da sua essência. (SGANZERLA, 2010, p. 42)

Entre Welles e Godard, tanto em suas análises de Cidadão Kane e Viver a Vida quanto na formulação de conceitos como "herói fechado" e "cinema impuro", Rogério Sganzerla parece querer dar um passo adiante às noções mais tradicionais de representação. Em um dois dos textos que escreveu sobre o filme de Godard, o crítico brasileiro valoriza o tratamento "despojado e econômico" como forma "para alcançar a absoluta ausência de sentido dos seres e objetos", pois desta maneira "a câmera não se preocupa em descrever a verdade dos locais, dos bares e ruas parisienses, como em Acossado" (SGANZERLA, 2010, p. 50), filme anterior de Godard. Em outras palavras, Rogério trata de um cinema que, opaco, se situa no limite da representação, solicitando outras operações de leitura que se coloquem, elas também, além da hermenêutica. Se a "câmera cínica" não oferece o sentido ou a verdade dos objetos, mas apenas seu regime de aparência, então a leitura alegórica, na medida em que prevê que o objeto está sempre em relação à outro discurso, não estaria destinada ao fracasso? Rogério responde a sua maneira: "Também não se pode transformar os objetos em símbolos ou metáforas, o que é típico do expressionismo e dos filmes de até poucos anos atrás." (SGANZERLA, 2010, p. 51). Não será o cinema de Rogério Sganzerla também um cinema sem metáforas?

Os textos de Sganzerla, de certa maneira, são desdobramentos de um mesmo embate que pode afinal ter vários nomes: opacidade versus transparência, manifestação versus essência, corpo versus alma, circularidade versus progressão, segredo versus esclarecimento, Acossado versus Viver a Vida, O Bandido da Luz Vermelha versus Vidas Secas, enfim. No entanto, o que parece ainda mais interessante são as maneiras como Rogério retorna a determinados temas e procedimentos, fazendo de sua forma de escrever uma máquina absolutamente obsessiva, mas também inserindo na experiência crítica um caráter provisório. Em outras palavras, não apenas o que diz, mas o modo como se propõe a dizer. O crítico Samuel Paiva, na apresentação que faz dos textos de Sganzerla, não deixa de perceber justamente esta dinâmica revisionista - que prefiro chamar de arqueológica, pois não está em jogo exatamente uma correção, e sim uma sobreposição de camadas - na maneira como Rogério opera inclusive com seus próprios matrizes. Ou seja, retornar aos mesmos lugares de partida "se constitui como recurso para se colocar em xeque tanto o ato de criar quanto o próprio produto da criação, numa poética de re(des)construção [...]” (PAIVA, 2010, p. 31). Será esta também a lição de seu cinema: o retorno incessante como maneira de rasura; o cinema não como produto fechado, portanto, mas processo, experiência. Retornar, a rigor, é 
reconhecer que a peça anterior está inacabada, como um puzzle ao qual falta uma peça, imagem recorrente nos textos críticos de Rogério; é reconhecer então que o destino de uma peça de arte é o fracasso. "Eu sei que fracassei", diz o bandido em uma de suas primeiras falas.

Basta pensar, por outro lado, como lembra o mesmo Samuel Paiva, que Rogério realizou nada menos do que quatro filmes, em um intervalo de quase vinte anos, em torno do filme não realizado de Orson Welles - Nem tudo é verdade, de 1986, Linguagem de Orson Welles, de 1991, Tudo é Brasil, de 1997, e finalmente O signo do caos, de 2003, seu último longa, e isso sem falar de Documentário, primeiro curta de Sganzerla, em que a referência ao cineasta norte-americano aparece em um cartaz de cinema, e no livro do qual foi organizador: O pensamento vivo de Orson Welles, também de 1986. Com Noel Rosa acontece praticamente o mesmo, com menos regularidade: Sganzerla realizou Noel por Noel, um misto de documentário e ficção, em 1980, e retornou ao compositor brasileiro em Isto é Noel Rosa, um curta, dez anos depois. Tal dinâmica, além de aparecer nos filmes e nos textos críticos - o conceito de câmera cínica retorna dez anos depois como câmera clínica -, aparece traduzida também dos filmes em relação aos próprios textos. Ou seja, não há hierarquia aqui, mas sobreposições entre peças soltas. Se ao ler os textos de Rogério temos a impressão de que o crítico escreve sobre os filmes que realizaria anos depois, como foi dito, também o contrário é verdadeiro, naturalmente - seus filmes reconfiguram um processo crítico.

Não há, entretanto, nestes retornos, o objetivo de esclarecimento, de definição de uma verdade que até então não havia sido percebida, por exemplo, ou mesmo a ideia de que é viável corrigir um erro anterior, e sim a noção de que o maior movimento que se pode fazer diante de um objeto é circular por ele, jamais penetrá-lo. Por isso talvez suas peças devam ser tomadas como inacabadas: para que seja necessário dar uma segunda volta ao redor do parafuso. Daí vem a maior diferença em relação à maneira como Ismail entende o cinema de Sganzerla, a saber: "Não se elimina o impulso de montar uma representação capaz de figurar uma totalidade”, escreve o crítico (XAVIER, 1993, p. 98). Isso, afinal, é o mais importante: na obra de Rogério, a ênfase está sempre no procedimento mesmo do retorno, no jogo da apropriação e da rasura, como se aí o cineasta delineasse para si uma espécie de procedimento cover. Como proposta de leitura dos filmes de Rogério Sganzerla, o cover interessa na medida em que explicita que a representação é uma moeda falsa. Ou seja, no cover, diferente do que ocorre na alegoria e na metáfora, a linguagem não quer se comportar como imagem de outra realidade, e sim como autoconsumação, por um lado, e processo parasitário, por outro. Desta 
maneira, até mesmo a expressão "terceiro mundo" pode ser lida de outra maneira, como um mundo que, sendo de terceira categoria, só pode ser um mundo falsificado, um mundo cover, e não somente subdesenvolvido. Enfim, o procedimento cover parece nos dizer, em outras palavras, ou talvez em sentido mais radical, aquilo que Rogério diz sobre a câmera cínica: ao mesmo tempo a busca pelo concreto e pela displicência, a aparência pura e o mau gosto, enfim, o esvaziamento pelo chavão.

\section{F for fake}

Devemos correr o risco então de imaginar que há algo da própria noção de cinema de Rogério Sganzerla que atravessa também o seu personagem principal, o bandido da luz vermelha, personagem que, inclusive, como os personagens do primeiro curta de Sganzerla, frequenta salas de cinema. É o que Julio Bressane, em um texto sobre seu parceiro, diz em outras palavras: "O cinema de Rogério Sganzerla fornece, além de uma bela forma de estilo, uma teoria do cinema feita por meio do cinema." "1 Tenho dúvidas sobre as noções de forma e estilo, que em si são polêmicas e solicitam uma história, mas concordo com o essencial: Rogério não abandona a teoria do cinema quando se torna cineasta. Neste caso, mais do que um bandido e um marginal, Jorginho talvez seja um falsificador: $F$ for fake, para citar o título do documentário de Orson Welles, realizado no ano de 1973, sobre um falsificador de obras de arte. Mas o que exatamente Jorginho falsifica? Melhor do que falsificar peças de arte, Jorginho falsifica a si próprio, falsifica a maneira de se colocar no mundo. Não mais a mimese, mas o próprio mimetismo.

Mais do que isso, Jorginho resiste a todas as tentativas de representá-lo, de torná-lo verdadeiro e conhecido - sua morte final, a um só tempo bizarra e heróica, parece um indício de que o bandido deve continuar sendo um objeto marginal, invisível mesmo, que não se deixa prender pela instituição da polícia e mesmo de ser apreendido pela instituição da história. Neste sentido, é interessante notar por exemplo a diferença do filme finalizado em relação ao roteiro original: neste, há um esforço maior de narrar o passado do bandido, de construir algum sentido de onde possa surgir sua vida infame; no filme, por motivos que julgo mais poéticos do que técnicos, estas cenas são cortadas. Seja como for, suas identidades, todas falsas, cabem em uma mala (que se perde no mar...) da mesma forma como as obras de Marcel Duchamp podem caber em uma valise; tornam-se miniatura, descarte. Jorginho aparece enunciado no letreiro do filme como um "monstro mascarado", um "Zorro dos

\footnotetext{
${ }^{1}$ BRESSANE, Júlio. Comentário sobre Sganzerla. Disponível em: http://www.itaucultural.org.br/ocupacao/. Acesso em: fev 2013.
} 
pobres". Se o espelho, por sua vez, é o objeto que melhor defende a noção de mimese, há uma cena no filme de Sganzerla em que o protagonista cobre seu reflexo com creme de barbear. A possibilidade de representá-lo, e de formar, portanto, uma imagem transparente de seu rosto, é lembrada apenas para que seja desfeita depois. Ou há vários espelhos, infinitos, pistas falsas de uma imagem que se perde no meio de todas as outras, ou não há espelho algum.

Em seu ensaio, Ismail Xavier faz o seguinte comentário: “ $O$ Bandido desliza em sua figuração da crise; sua opção é a agilidade, a fluência que prolifera imagens, referências. Não por acaso, tal proliferação envolve Orson Welles, matriz deste jogo de estilhaçar a identidade, mestre das parábolas em que a crise não resolvida, o enigma insondável, se transforma em prazer de simulação, vertigem bem-vinda de um jogo de aparências que esvazia o conteúdo substancial do EU como ilusão" (XAVIER, 1993, p. 92). E depois Ismail ainda enfatiza o modo como aparece o uso dos espelhos, em uma análise tão precisa quanto destruidora, da noção de totalidade que o próprio Ismail acredita:

$\mathrm{Na}$ afinidade do jogo de aparências, não falta, em $O$ Bandido, o dado da multiplicação das vozes (o mosaico de perspectivas), o traço do colecionador (o mundo de Kane é gigantesca obsessão coletora) e o gosto pela ostentação de metáforas visuais da identidade (são os compartimentos do Luz e, em especial, a Casa Azul, a fortaleza- santuário do J.B., espécie de Xanadu no cenário da Boca do Lixo). Nos filmes de Welles, a imagem emblemática da crise é a do espelho dentro do espelho, a reprodução em abismo das mesmas figuras a desestabilizar o campo visível: [...] (XAVIER, 1993, p. 92).

A idéia de falsificação aparece n' $O$ Bandido segundo perspectivas, temas, imagens e procedimentos diversos. A rigor, é possível argumentar que Jorginho nem mesmo é um bandido, pois também se comporta como se fosse um herói - um “Zorro dos pobres”, segundo alguma voz em off anuncia nos primeiros minutos. A indecisão entre bandido e herói, aliás, será um motivo constante no filme. De início, a escolha de um ator com perfil de galã espanhol não é aleatória: o bandido é um sedutor, uma espécie de pastiche de Don Juan, que conquista até mesmo mulheres bonitas e interessantes. Depois, ao roubar também uma calcinha e um presunto, além de objetos valiosos, há algo nele que parece se humanizar. Em outro momento, o bandido elogia o tempero da comida que uma de suas vítimas prepara para ele, a pedidos: "bom tempero, madame". O bandido, enfatizando o lado delicado de seu caráter, também se interessa por aprender receitas de bolo. A própria voz do bandido, ao expressar uma frustração do tipo "fim de carreira", como nota Ismail, também deixa escapar uma ponta de fraqueza, humanidade. Enfim, a fórmula ambígua do bandido está mais ou menos exposta em outra frase que aparece no letreiro, frase afinal tão característica do cinema de Rogério: "um gênio ou uma besta". 
De outra maneira, a proliferação de identidades falsas que o bandido lança mão para sua estratégia de disfarce, identidades que estão ligadas tanto a seu passado quanto ao presente da narrativa, aparece como forma de desnaturalização de um regime de identidade estável. Para enfatizar mais a dúvida, estas identidades são apresentadas a partir de vozes e pontos de vistas distintos: tanto a voz em over quanto os noticiários e até mesmo o próprio bandido e outros personagens, cada um a sua maneira, enunciam qualquer coisa, muitas vezes em forma de perguntas, sobre estas identidades; inclusive a nacionalidade do bandido é tema de mistério: "Paraguaio, brasileiro, cubano ou mexicano?" Certamente um bandido latinoamericano. Por sua vez, as vozes se sobrepõem umas às outras, como se fossem camadas (o significante over, do inglês, também significa camadas) que servem não para revelar a verdade sobre um objeto, mas para esconder ainda mais o seu rosto, como é a função da máscara que o bandido usa. E como é também a função dos pseudo-nomes.

A noção de falsidade tem relação também com o discurso mentiroso, típico de personagens sem caráter e sedutores, do qual não se deve esperar alguma confiança, mas somente a performance vazia, os jogos de linguagem. Seja como for, nem mesmo Jorginho tem certeza do que diz, e devemos acreditar nele: "Não tenho certeza de mais nada; aliás, nunca tive", diz. A oscilação entre sinceridade e mentira, neste sentido, como consequência até natural da estratégia das identidades falsas, também parece uma oscilação essencial do bandido. Quando conhece Janete, personagem de Helena Ignez, o bandido diz o seguinte a ela: "Minha mãe me quis abortar, por isso eu nasci assim. Você vai me desculpar se isso que estou dizendo não seja verdade, mas uma simples mentira". Ou seja, mais do que ser essencialmente mentiroso, o bandido coloca a mentira no centro da linguagem, e nisso parece dizer que a mentira, mais do que uma forma - pois aí ela ganharia seu lugar - é uma possibilidade. "Você vai me desculpar $s e$ ", diz o bandido. A falsificação, desta maneira, como a falsificação de dinheiro, pode ser também de um discurso ou do próprio cinema. Em uma frase atribuída a Welles, que aparece no documentário Nem Tudo é Verdade, se afirma justamente, com ironia devastadora, que a "A máquina de filmar é o instrumento mais mentiroso inventado pelo homem".

Quando um dos personagens fala olhando em direção à câmera, enfim, convocando o leitor a uma interlocução direta - ou seja, não protegida pela quarta parede da tela - então é a própria separação entre ficção e realidade que se quebra. Este recurso será radicalizado em outros filmes de Rogério, mas sua função aparece com clareza desde $O$ Bandido: não se tem nem mesmo certo, ou não se quer ter, de que a Boca de Lixo é uma ficção. Em outras 
palavras, o leitor deixa de ser testemunha e passa a ser um cúmplice. No entanto, não se deve confundir isso com um realismo convencional realismo. A garantia da mimese depende de uma segurança entre as palavras e as coisas. Para haver alegoria, pensando ainda nos termos de Ismail, é necessário que haja separação, que um espaço simbólico apenas referencie o outro, que a arte não se confunda com a vida. Seja como for, no limite da falsificação, Sganzerla faz confundir até mesmo os gêneros cinematográficos: ficção e documentário são híbridos, mas não apenas eles. O próprio cineasta escreve sobre este desejo em um manifesto escrito em 1968, durante as filmagens de $O$ Bandido, por um Cinema Fora da Lei, usando expressões como filme-soma, mixagem e fusão:

\footnotetext{
Meu filme é um far-west sobre o Terceiro Mundo. Isto é, fusão e mixagem de vários gêneros. Fiz um filme-soma; um far-west mas também musical, documentário, policial, comédia (ou chanchada?) e ficção científica. Do documentário, a sinceridade (Rossellini); do policial, a violência (Fuller); da comédia, o ritmo anárquico (Sennet, Keaton); do western, a simplificação brutal dos conflitos (Mann). (SGANZERLA, 2008, p. 22)
}

Enfim, o que parece ser colocado em debate é a idéia de que a linguagem, na medida em que entra no jogo circular da falsificação - afinal o que a falsificação faz é inserir algum ruído estranho na transparência do signo, borrar a verdade da imagem - deve suspender justamente o compromisso com a metáfora. Em outras palavras, o cinema de Rogério Sganzerla não reproduz o visível, tampouco o tematiza; ele faz o visível. Finalmente, como supostamente diz Orson Welles em Nem tudo é verdade, representado pelo compositor Arrigo Barnabé, e diz segundo a imaginação de Sganzerla - o Brasil produz o melhor whisky falsificado do mundo. Como a frase feita e a piada pronta, variações do whisky falsificado, recursos explorados por Sganzerla em absolutamente todos os seus filmes - talvez com alguma ênfase nos filmes sobre Noel Rosa, que se torna um frasista inverterado - também um whisky falsificado não é metáfora de nada. Um whisky falsificado é só um whisky falsificado.

\section{Over, a voz}

A voz, no cinema de Sganzerla, principalmente a narração over, mas também a construção da voz dos atores, muitas vezes dita com descompensado exagero, faz um papel absolutamente deformador. Na deformação da voz, o que se deforma também é a própria interpretação naturalista. Em grande parte, a voz é responsável pela atribuição de um cinema de excesso, expressão que o próprio Rogério usou para mencionar o cinema de Orson Welles, mas também do Zé do Caixão: "Cineasta do excesso e do crime, José Mojica Martins me apontou a poesia furiosa dos atores do Brás, das cortinas e ruínas cafajestes e dos seus 
diálogos aparentemente banais" (SGANZERLA, 2008, p. 17) No cinema de Rogério, a voz ganha quase um corpo visual, tamanho seu peso nas cenas. Nota-se, por exemplo, que nos roteiros há indicações para que o texto seja dito por uma "voz rápida e vulgar" e até mesmo por uma "voz fanhosa" - e sendo a voz parte de um projeto maior de som, a música também deve ser "nervosa, explosiva". Um dos textos também é marcado com a rubrica "o mais sensacionalista possível" (SGANZERLA, 2008, p. 38). Os personagens de Sganzerla gritam, são loucos, histéricos ou boçais, e o grito se torna então o oposto do estilo e da moderação clássica.

Em um texto sobre Welles, "O legado de Kane", Rogério escreve que beleza é justamente excesso e exuberância: "Em Orson Welles, como em William Blake, a beleza é a exuberância. Em todos os sentidos: exuberância técnica, acúmulo de personagens, de intenções históricas, histriônicas, de montagem, exuberância do mau gosto e, enfim, a exuberância do cinema americano" (SGANZERLA, 2010, p. 96). Em Welles, por sua vez, a voz assume dimensões variadas, sempre fundamentais. Não é em vão, primeiro, o interesse que o cineasta americano nutre pelo teatro e a ópera: "Considero a ópera a experiência do absoluto. A voz é um elemento comovente", disse Welles em uma entrevista. (SGANZERLA, 1986, p. 85). Mas se o cineasta americano se interessa pela ópera, o rádio também terá importância fundamental para sua obra. Antes de filmar Cidadão Kane, em uma história que virou mito na história do rádio e mesmo na história do cinema, Welles tornou-se famoso por gravar uma rádio novela que criou pânico nos Estados Unidos por simular, com sensacionalismo, uma invasão de extra-terrestres:

[...] na noite do dia 30 de outubro, a história que vai ao ar é A Guerra dos Mundos, de H. G. Welles. O elenco, sob as ordens de Welles, carrega na interpretação e o pânico toma conta do país de costa a costa. A população começa a ver marcianos por toda parte. Suicídios, partos prematuros e fuga para as montanhas são as sequelas imediatas. A polícia invade o estúdio, mas como a lei não prevê aquele tipo de delito, não há como punir Welles [...] (Idem, Ibidem, p. 26)

No rádio, além de mais carregada, caricatural, muitas vezes sensacionalista mesmo, a voz precisa ser rápida, como nos quadrinhos e como no cinema, afinal - pelo menos é isso que acontece nos cinemas de Welles e Sganzerla. No entanto, há o senso comum de que narração em off ("voice over" é o termo técnico) não serve para o cinema justamente por ser um procedimento do rádio. Nem Tudo é Verdade, seja como for, inicia exatamente assim: uma voz over, forçada, meio gritada e meio roca, com tom de reportagem, pois se trata de uma falsa reportagem, dizendo um texto sobre Shakespeare. Logo depois, em uma interpretação magnífica de Arrigo Barnabé, Orson Welles aparece como um personagem histriônico, 
sempre com sotaque carregado, se sobrepondo a uma colagem de sons que vai desde o samba até um jazz de filme noir. Entretanto, o mesmo não acontece no segundo longa sobre Welles: Tudo é Brasil. Com um arquivo maior sobre a passagem do cineasta americano pelo país, que Rogério Sganzerla descobre após a conclusão do primeiro filme, pode-se dizer que existe agora uma aproximação maior a um caráter mais documental da história, e até mesmo a um procedimento mais tradicional de realizar documentário, embora nem tanto. A voz over do primeiro filme (a voz em off, por um lado, e extravagante, por outro) é substituída por arquivos sonoros que são apropriados pelo filme, com a voz original de Welles e outras figuras que Welles conheceu no Brasil, como Carmen Miranda e Grande Othelo.

Em $O$ Bandido, como se sabe, a narração em off atravessa todo o filme e tem funções narrativas primordiais, como a criação do mito em torno do bandido, a proliferação do senso comum e mesmo um ritmo narrativo veloz. De outro modo, a escolha por uma dicção gritada da voz narrativa, algo como acontece também nas rádio novelas, parece servir para desnaturalizar o discurso onisciente do romance moderno, que seria responsável pela verdade, ou seja, palavra final que tudo sabe e que serve portanto para organizar todos os consensos. De qualquer maneira, mesmo a narração exagerada parece se aproximar ainda de uma reportagem, recolocando a dicotomia verdadeiro/falso. Seja como for, a voz narrativa em $O$ Bandido se apresenta como mais uma voz entre as outras, que se confunde, se atropela, tropeça, cria tensões. Em outra anotação sobre $O$ Bandido da Luz Vermelha, o próprio cineasta escreve: "Um filme cacofônico - à beira da afasia." O grito e a afasia, neste caso Jimi Hendrix, por um lado, e João Gilberto, por outro - se complementam pela oposição.

Pois é também em Jimi Hendrix - "o artista mais importante do século" - que Sganzerla deve reconhecer, de acordo mais uma vez com a percepção de Jair Fonseca, a importância do grito e da deformação do som: a microfonia. Jimi Hendrix provavelmente foi o primeiro instrumentista de rock a usar o ruído do microfone, que seria o equivalente do grito, como possibilidade de criação. A microfonia é justamente a impossibilidade da articulação da voz, do canto, da arte dramática, ou seja: da falta de coincidência entre som e sentido. Em uma palavra, a microfonia é a troca da articulação pelo ruído. O grito, a desarticulação da sintaxe, desta maneira, fica sendo síntese de uma idéia de cinema; muito embora no cinema de Sganzerla pareça existir também sempre um contrário: o canto afásico de João Gilberto, a síntese, a moderação, a autoconsumação, quase o silêncio. Mesmo em um texto sobre Jimi Hendrix, Sganzerla enfatiza também aquilo que em sua música e em suas 
letras consiste em elegância e concisão: "Suas letras devem ser ouvidas como um ideograma, com grande elegância e concisão de forma - referindo-se ao essencial [...]"2.

Por sua vez, em Isto é Noel Rosa, o grito se traduz na tosse, fio narrativo que recorre todo filme. Além de doente, Noel aparece também, nas cenas ficcionais criadas por Sganzerla, como um arruaceiro. De fato, nas primeiras cenas, depois de uma gravação em que João Gilberto canta Feitiço da Vila, Noel aparece chutando uma lata pelas ruas de Vila Isabel e quebrando garrafas de cerveja no Carnaval, provavelmente bêbado. A tosse, além da parte maldita de um corpo doente, é a impossibilidade da fala, expressão autoreferente e de algum modo performática que não diz nada além da própria condição de fragilidade. Neste caso, aliás, a tosse é o elemento sonoro que evoca a morte (indício tão importante para todo o cinema de Sganzerla) como um fantasma que paira pela vida de Noel. A tosse é o que restou de um corpo após a doença, o que restou do seu canto em contato com a morte - a sua parte over, digamos assim.

Afinal, o próprio significante over traz uma ambiguidade que parece muito produtiva e incontornável para a leitura do cinema de Rogério Sganzerla. Se por um lado over é um adjetivo que se refere a algo acabado e concluído, também se refere, diferente do end, a algo excessivo, suplementar, a uma matéria que resta; e nos sugere ainda, a partir talvez de uma noção de arqueologia, o sentido de camadas, capas e coberturas. Em outras palavras, se uma obra é concluída, seja um filme ou um texto crítico, há algo que nela que resta enquanto elemento intratável e desarticulado, a última peça do puzzle que nos faz retornar e sobretudo nos faz reler. As camadas são também de gênero: faroeste, policial, documentário, comédia, ficção científica, musical, enfim, tudo no mesmo liquidificador, diluídas - "um filme-soma", em suas próprias palavras. Se pensarmos ainda que nos filmes de Sganzerla, principalmente nos documentários, todos os materiais que envolvem sua contrução (imagem, música, texto) aparecem dissociados entre si - diferente de um realismo convencional, neste sentido, onde tudo deságua na construção de um sentido único -, pode-se pensar na radicalização daquilo que no seu cinema é uma narrativa feita em camadas. Se o cinema é um puzzle, Rogério parece nos ensinar um pouco mais do que isso: que faltará sempre uma peça. O nome da peça talvez seja o mesmo daquele enigma de Orson Wells, "Rosebud".

\section{Referências}

\footnotetext{
${ }^{2}$ SGANZERLA, Rogério. Jimi, gênio total. Disponível em: http://www.itaucultural.org.br/ocupacao/. Acesso em: fev 2013.
}

Anu. Lit., Florianópolis, v.19, n. 1, p. 158-174, 2014. ISSNe 2175-7917 
MACHADO DE ASSIS, Joaquim Maria. "Memórias Póstumas de Brás Cubas". In: Obra Completa. V. I: Romance. Rio de Janeiro: Nova Aguilar, 2008.

BRESSANE, Júlio. Comentário sobre Sganzerla. Disponível em: http://www.itaucultural.org.br/ocupacao/. Acesso em: fev 2013.

FONSECA, Jair Tadeu. In: Edifício Rogério. V. 2. Florianópolis: Editora da UFSC, 2010.

PAIVA, Samuel. In: Edifício Rogério. V. 1. Florianópolis: Editora da UFSC, 2010.

SCHWARCZ, Roberto. Um mestre na periferia do capitalismo: Machado de Assis. São Paulo: Livraria Duas Cidades, 1990

SGANZERLA, Rogério (Org.). O pensamento vivo de Orson Welles. São Paulo: Martin Claret, 1986.

Por um cinema fora da lei. In: Roteiro d'O Bandido da Luz Vermelha (Coleção Aplauso). São Paulo, Imprensa Oficial. 2008.

In: Edifício Rogério. V. 1. Florianópolis: Editora da UFSC, 2010.

XAVIER, Ismail. Alegorias do Subdesenvolvimento. São Paulo: Brasiliense, 1993.

\section{Site}

Ocupação Sganzerla. São Paulo, Itaú Cultural, julho 2010. Disponível em: http://www.itaucultural.org.br/ocupacao/

[Recebido e aceito para publicação em dezembro de 2013]

\section{Sganzerla Cover}

Abstract: In this article, I used two different concepts to read Rogerio Sganzerla's film work: cover and over. So I started it out from a controversy related to an essay called Allegories of underdevelopment, written by Ismail Xavier, in which the critic sees Brazilian cinema of the 60 's through the concept of allegory. Then I took another look at a series of critical texts written by Sganzerla trying to rethink the ideas of "empty hero" and suggesting a new relationship between movie and time. With all that, I tried to build up an articulation among these ideas with some leading-edge procedures such as counterfeiting, copying, cliché and collage. And finally I tried to show that the voice is used in a way as to deform the naturalistic interpretation in Sganzerla's work.

Keywords: Sganzerla. Cover. Over.

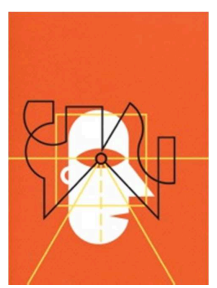

